\title{
Simulating the Effects of Surface Roughness on Reinforced Concrete T Beam Bridge under Single and Multiple Vehicles
}

\author{
Rahul Kalyankar and Nasim Uddin \\ Department of Civil Construction and Environmental Engineering, University of Alabama at Birmingham, Birmingham, AL, USA \\ Correspondence should be addressed to Rahul Kalyankar; krahul2807@gmail.com
}

Received 22 June 2016; Accepted 2 August 2016

Academic Editor: Lucio Nobile

Copyright ( 2016 R. Kalyankar and N. Uddin. This is an open access article distributed under the Creative Commons Attribution License, which permits unrestricted use, distribution, and reproduction in any medium, provided the original work is properly cited.

\begin{abstract}
This research focuses on the application of the spatial system of finite element modeling for the vehicle-bridge interaction on reinforced concrete US Girder Bridge in order to obtain the effect of surface roughness. Single vehicle and multiple vehicles on reinforced concrete $\mathrm{T}$ beam bridge were studied with variable surface roughness profiles. The effects of six different surface roughness profiles (very good, good, measured, average, poor, and very poor) were investigated for vehicle-bridge interaction. The values of the Dynamic Amplification Factor (DAF) were obtained for single and multiple vehicles on T Beam Bridge for different surface roughness profiles, along with the distances between the axles of heavy vehicle. It was observed that when the bridge has very good, good, measured, and average surface roughness, the DAF values for the single vehicle over the bridge were observed to be within acceptable limits specified by AASHTO. However, for the bridge with multiple vehicles only very good and measured surface roughness profiles showed a DAF and vehicle axle distances within the acceptable limits. From the current studies, it was observed that the spatial system showed reliable responses for predicting the behavior of the bridge under variable road surface roughness conditions and was reliable in vehicle axle detection, and therefore, it has a potential to be use for realistic simulations.
\end{abstract}

\section{Introduction}

The vehicle's interaction with the bridge is very complicated issue. The vehicles' rotating tires exert load on the bridge while vehicle in motion. Since the vehicle is a complex assembly of various components, the vehicle induced motion creates dynamic forces in the suspension and tire assembly which gets transferred to the bridge. The interaction between vehicle wheels and bridge is also dominated by bridge surface irregularities. The interaction between the vehicle's tire and the rough bridge surface causes the vehicle to move in different directions, thus causing vibration in the bridge. The schematic of surface irregularities under a vehicle during vehicle-bridge interaction is as shown in Figure 1.

As shown in Figure 1, the vehicle passing over the irregular surface swings the vehicle axles, thus creating significant amount of shaking in the bridges [1-4]. It was observed that, as a result of surface roughness present during vehicle-bridge interaction, the dynamic forces could increase up to $90 \%$ [5]. The surface roughness profile used for obtaining dynamic forces is created using vehicle-structure mathematical model under full probabilistic formulation in frequency domain that considers dynamics of vehicle-bridge interaction. The vehicle velocities, combined with surface irregularities, significantly increase the magnitude of the vibration. Along with the velocities, the number of vehicles present over the bridge also severely affects the dynamic forces [6].

As per AASHTO bridge specification, the static responses of bridges are magnified by $33 \%$ to approximate dynamic responses of the bridge for vehicle induced dynamic forces [7]. This magnification factor is generally known as Dynamic Amplification Factor (DAF) as per Euro code or Dynamic Impact Factor (DIF) as per AASHTO and is given by (1) and (2):

$$
\mathrm{DAF}=\frac{S_{d}}{S_{s}}=1+\mathrm{DIF},
$$


TABLE 1: Road surface roughness coefficients [10-12].

\begin{tabular}{lc}
\hline $\begin{array}{l}\text { Road surface roughness } \\
\text { classification }\end{array}$ & $\begin{array}{c}\text { Road surface roughness } \\
\text { coefficient }\end{array}$ \\
\hline $\begin{array}{l}\text { Very good surface roughness } \\
\text { (VGSR) }\end{array}$ & $2 \times 10^{-6}-8 \times 10^{-6}$ \\
Good surface roughness (GSR) & $8 \times 10^{-6}-32 \times 10^{-6}$ \\
Average surface roughness (ASR) & $32 \times 10^{-6}-128 \times 10^{-6}$ \\
Poor surface roughness (PSR) & $128 \times 10^{-6}-512 \times 10^{-6}$ \\
$\begin{array}{l}\text { Very poor surface roughness } \\
\text { (VPSR) }\end{array}$ & $512 \times 10^{-6}-2048 \times 10^{-6}$ \\
\hline
\end{tabular}

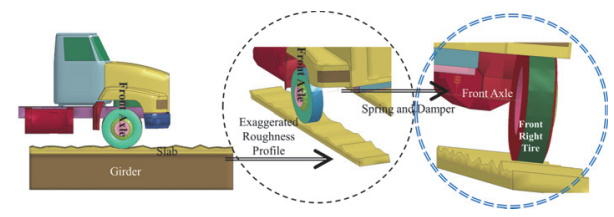

FIGURE 1: Vehicle on rough bridge surface during vehicle-bridge interaction.

where $S_{d}$ : dynamic strain at the center or sensor location, $S_{s}$ : static strain at the center or sensor location:

$$
I=\frac{50}{L+125}
$$

where $I$ : impact factor and $L$ : length of bridge $(\mathrm{m})$.

Using (1) and (2), the impact factor can be obtained for any bridge. However, the vehicle bouncing as a result of surface irregularities is neglected in the DAF and a uniform factor is applied over the bridge regardless of bridge type, nature of vehicular traffic, and amount of surface irregularity over it [7-9].

There were numerous efforts taken by researchers in the past to determine the surface roughness on the bridge by classifying them into different profiles [10-12]. Based on previous studies, the classification of road roughness was done into five categories using a road surface roughness coefficient as given in Table 1 [10-12].

The coefficients as listed in Table 1 were obtained using a Power Spectral Density (PSD) function. In addition to this, efforts were also taken by past researchers to measure the road surface roughness on actual bridge [13]. The road surface roughness profile measured on actual site (MSR), along with five road surface profiles (VGSR, GSR, ASR, PSR, and VPSR) obtained using PSD, is as shown in Figures 2(a)-2(f).

From Figures 2(a)-2(f), it can be observed that the profiles obtained from measured road surfaces on actual bridges closely resemble the average road surface profile in terms of magnitude of trough or crest. Numerous studies were conducted by the past researchers using these road surface roughness profiles to obtain bridge responses $[9,13]$. Numerous simulations were carried out on the bridges for vehicle-bridge interaction with variable roughness surface profiles using finite element modeling (FEM). AASHTO HS20-44 along with a simply supported $\mathrm{T}$ beam bridge modeled using orthotropic plate theory was used for the analysis [9]. However, while attempting to obtain the DAF, these studies did not address multiple vehicle scenarios, and the vehicle path was assumed to be in the center of the bridge. In addition to this, the variable roughness surface was not addressed in the study [9]. To this end, another study on the application of roughness with multiple vehicles with the change in roughness profile from very good to very poor showed an increase in the DAF [13]. However, the grillage method was used for the bridge FEM which possesses some drawbacks in case of complicated bridge structures [14]. During previous studies for obtaining the DAF, the focus was only on the bridge strain responses, and the effect of surface roughness on axle detection was not addressed in the previous studies.

Therefore, due to these limitations of previous analysis, an alternate approach of Simplified 3 Dimensional Finite Element Model (3D SFEM) using spatial system was proposed in the previous work for obtaining the effect of surface roughness with single and multiple vehicle scenarios [15]. For the application of the spatial method, the most common type of reinforced concrete T beam bridge on US 78 was selected, along with the ALDOT 5 Axles Truck as heavy vehicle, as described in Section 2.

\section{Spatial System for US Girder Bridges and Heavy Vehicle}

The simplified 3D FEM (3D SFEM) of the US $78 \mathrm{~T}$ Beam Bridge (designated as US 78 for the rest of the article) was developed using spatial method. For the US 78 bridge, the geometric information is provided by Alabama Department of Transportation. The geometry of US 78 used for the development of 3D SFEM is as shown in Figure 3.

The 3D SFEM of US 78 was developed using information provided by ALDOT as shown in Figure 3. Along with the geometric information, the material properties were supplied by ALDOT and are as listed in Table 2.

Using the properties and geometric information provided in Figure 3 and Table 2, the 3D SFEM of US 78 was developed. The shell elements used for slab and for the girder bottom shell are assigned with six degrees of freedom per nodes. Similarly, the beam elements used for reinforcements and for the web are also assigned with six degrees of freedom per nodes. For the support, five and six degrees of freedom were assigned at each support, thus allowing the movement in longitudinal direction at one end. The 3D SFEM of US 78 was verified for deflection and natural frequencies in order to use it for vehicle-bridge interaction [15]. The 3D SFEM of US 78 is as shown in Figure 4.

As shown in Figure 4, the discretization of various components of US 78 was carried out using different types of elements. For the sake of brevity, the 3D SFEM of only one girder is shown in Figure 4. Along with US 78, the 3D SFEM of ALDOT 5 Axles Truck, representing the common heavy vehicle on US highways, was modeled using spatial method. The schematic of ALDOT 5 Axles Truck used for finite element modeling is as shown in Figure 5.

The 3D SFEM of ALDOT 5 Axles Truck developed using properties as shown in Figure 5 was verified for mass 
TABle 2: Properties of Components of US 78.

\begin{tabular}{|c|c|c|c|c|c|c|c|c|c|}
\hline \multirow{3}{*}{ S. Number } & \multirow{3}{*}{ Component } & \multirow{3}{*}{ Actual size (mm) } & \multirow{3}{*}{ 3D SFEM size $(\mathrm{mm})$} & \multirow{3}{*}{ Element type } & \multicolumn{5}{|c|}{ Material properties } \\
\hline & & & & & \multicolumn{2}{|c|}{$\rho\left(\mathrm{kg} / \mathrm{m}^{3}\right)$} & \multicolumn{2}{|c|}{$E(\mathrm{GPa})$} & \multirow{2}{*}{$v$} \\
\hline & & & & & Actual & FEM & Actual & FEM & \\
\hline 1 & Deck slab $(t)$ & 150 & 225.5 & Shell & 2400 & 2020 & 25 & 24 & 0.22 \\
\hline 2 & T-Beam $(t)$ & 940 & 947 & Beam & 7850 & 2140 & 25 & 31.3 & 0.22 \\
\hline 3 & Beam MR $(\Phi)$ & 36 & 51 & Beam & 7850 & 7850 & 210 & 210 & 0.3 \\
\hline 4 & Beam Tr R $(\Phi)$ & 36 & 51 & Beam & 7850 & 7850 & 210 & 210 & 0.3 \\
\hline 5 & Girder BS $(t)$ & - & 10 & Shell & - & - & - & 25 & 0.22 \\
\hline
\end{tabular}

MR: main reinforcement; Tr R: top reinforcement; Girder BS: girder bottom shell; $t$ : thickness.

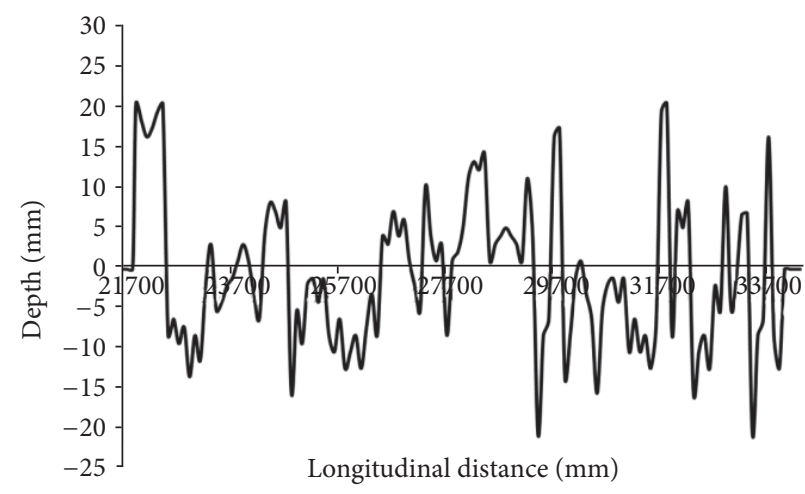

(a) Measured surface roughness (MSR) profile

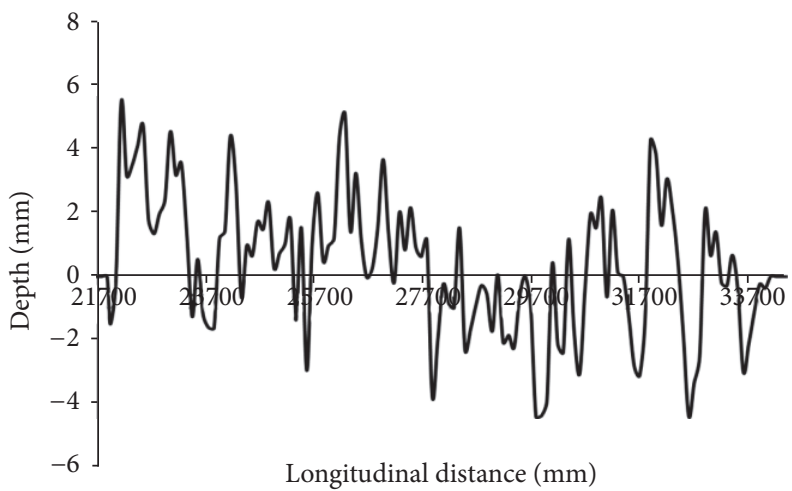

(c) Good surface roughness (GSR) profile

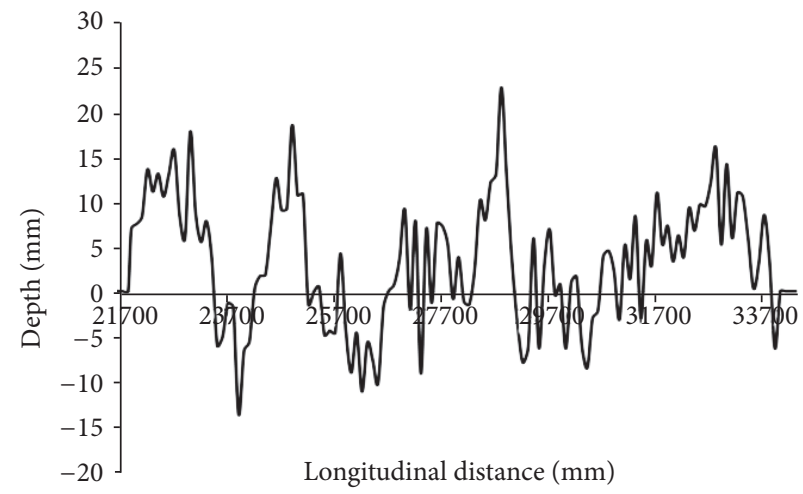

(e) Poor surface roughness (PSR) profile

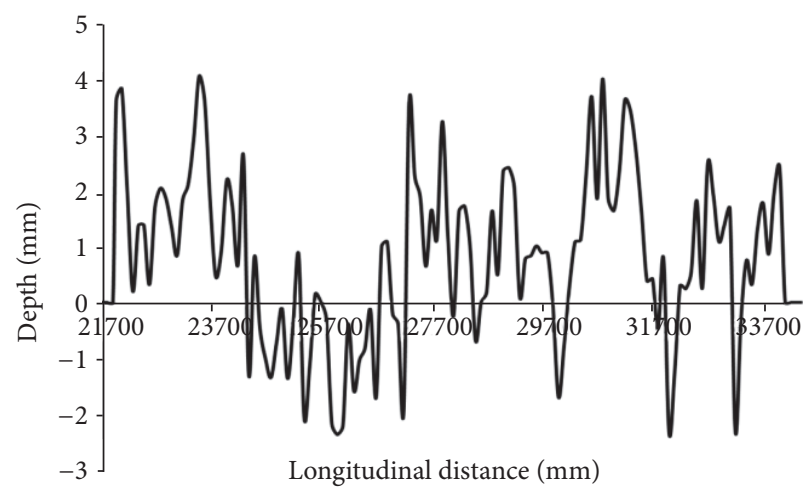

(b) Very good surface roughness (VGSR) profile

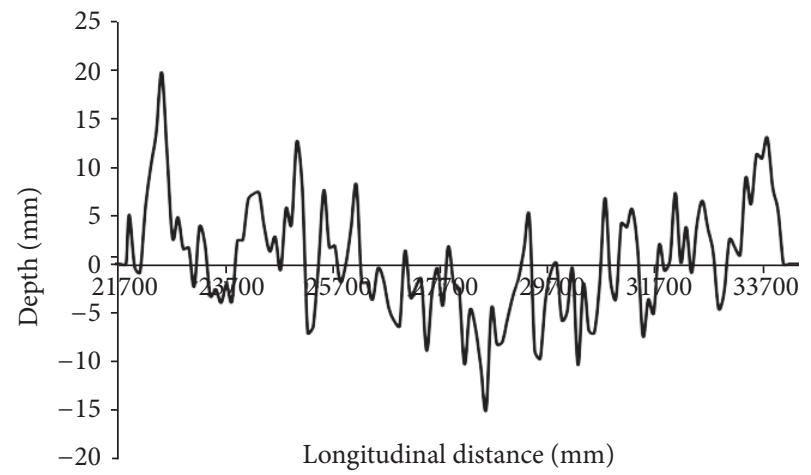

(d) Average surface roughness (ASR) profile

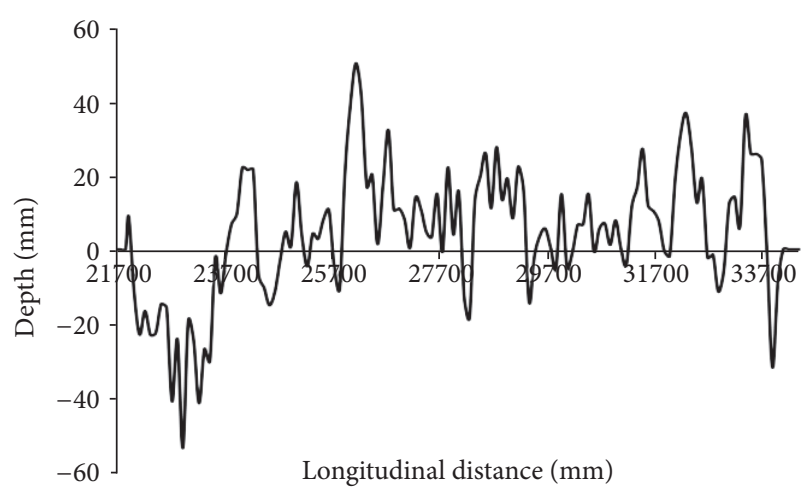

(f) Very poor surface roughness (VPSR) profile

FIGURE 2: Road surface roughness profiles for vehicle-bridge interaction. 

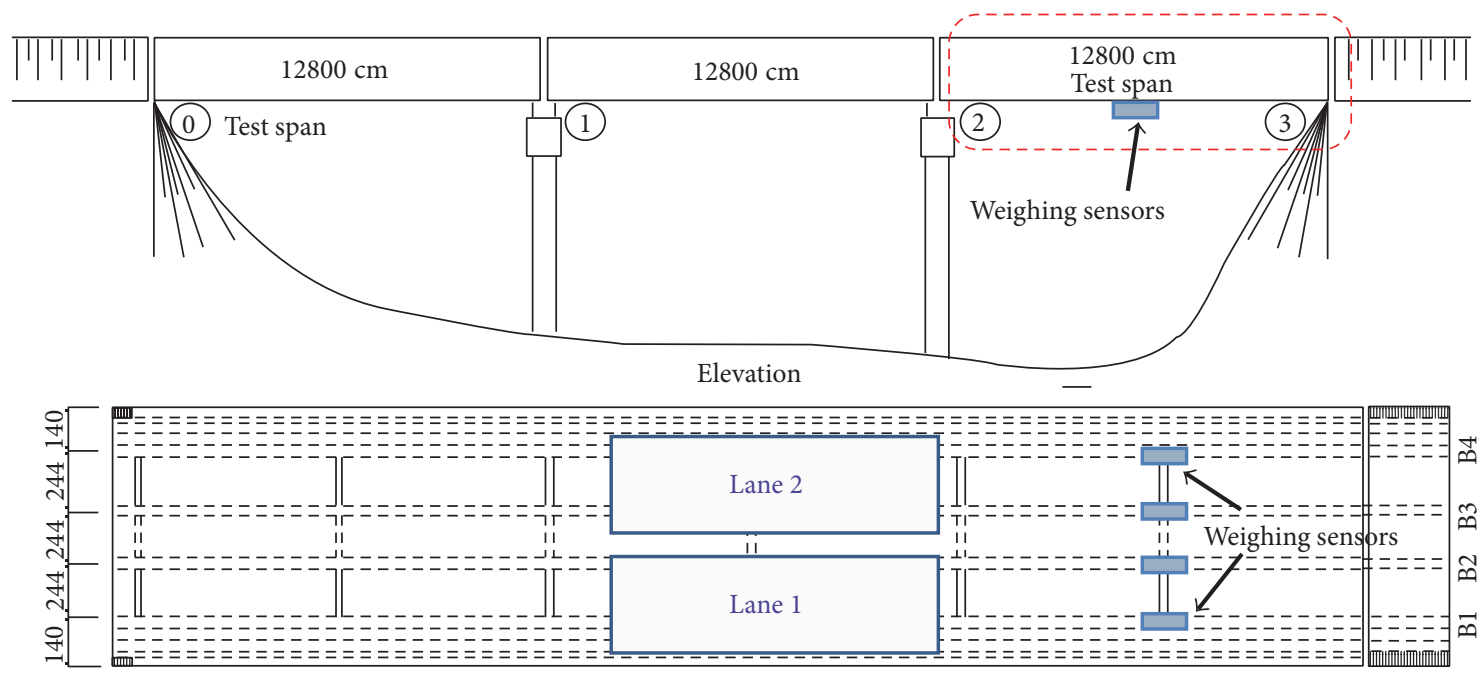

Plan

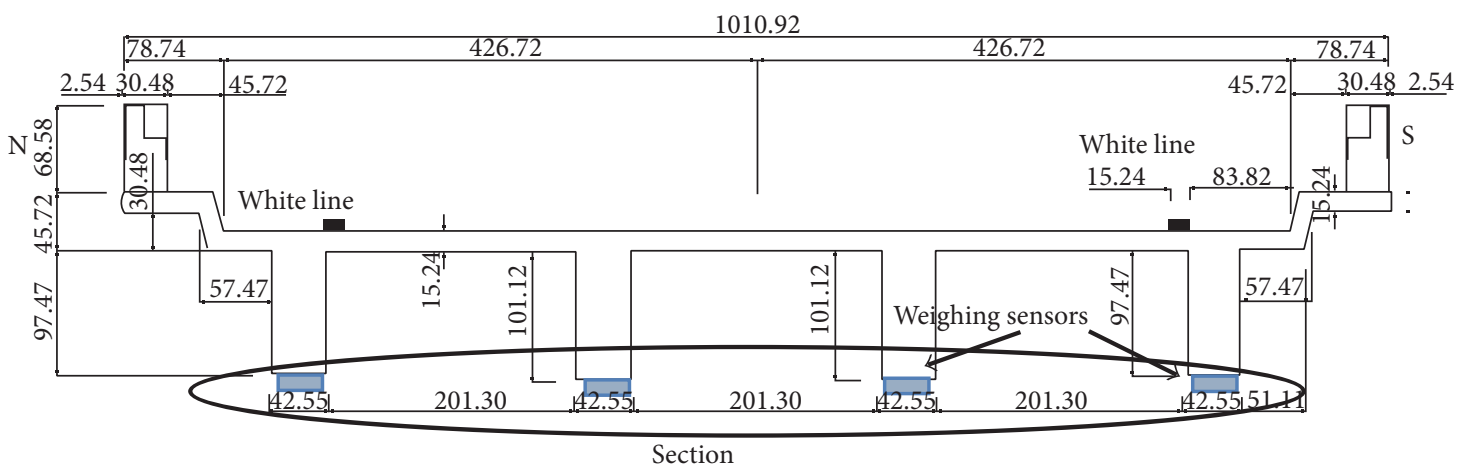

FIGURE 3: Detailed schematic of US 78.

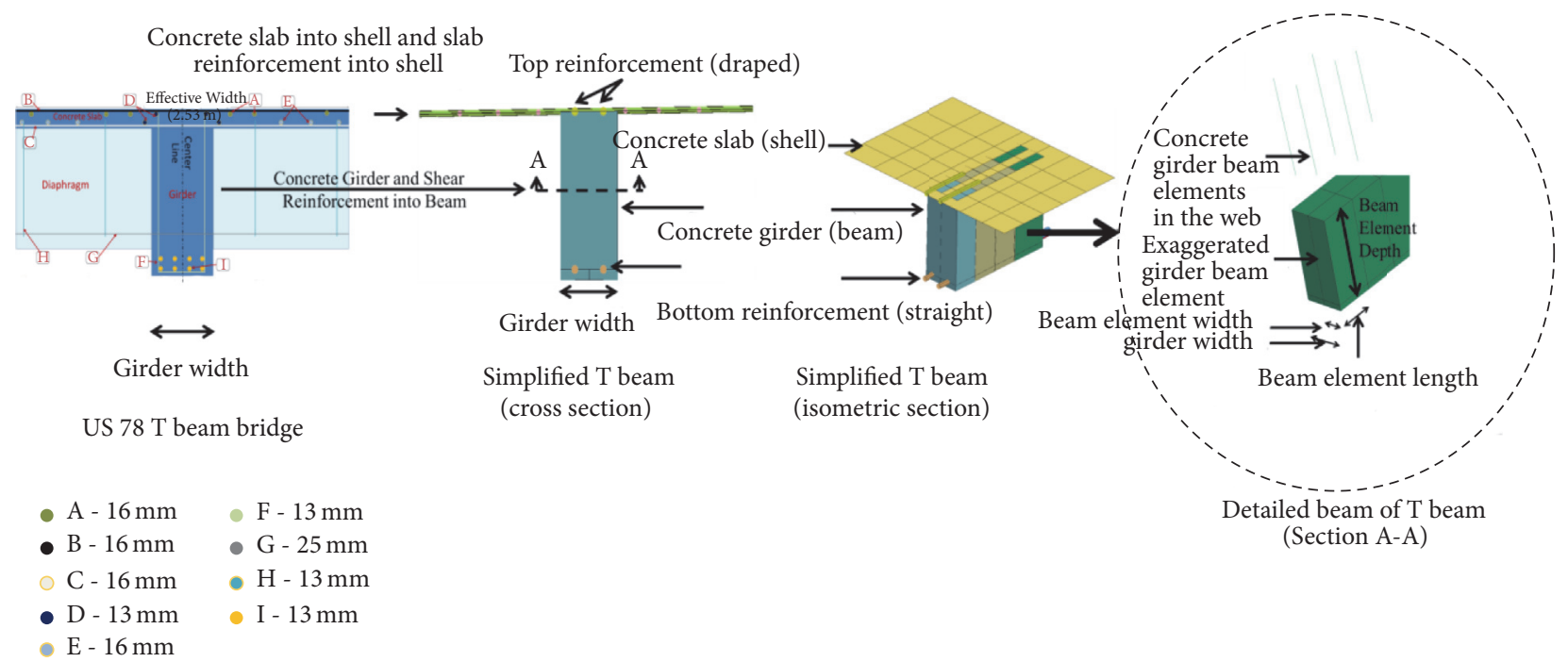

FIGURE 4: Detailed views of discretized US 78 used for 3D SFEM.

distribution. For the sake of conciseness, the properties of various components of the vehicle are not included in this work and can be obtained from previous research [15]. The 3D SFEM of heavy vehicle used for vehicle-bridge interaction is as shown in Figures 6(a) and 6(b).
As shown in Figures 6(a) and 6(b), the vehicle was discretized using mass, beam, and discrete elements. The detailed view of the front axle of a heavy vehicle consisting mass, beam, and discrete elements is as shown in Figure 6(b). The vehicle-bridge interaction was carried out using US 78 


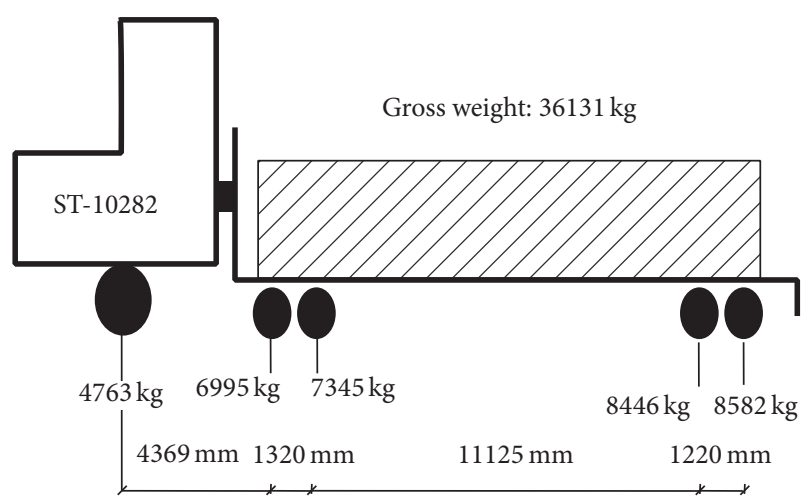

FIgURE 5: Schematic of ALDOT 5 axles fully loaded truck used as heavy vehicle.

as shown in Figure 4 and heavy vehicle as shown in Figures 6(a) and 6(b). For the vehicle's interaction with the bridge, RAILTRAIN contacts were used. The RAILTRAIN contact is a node-to-beam type contact which describes the interaction of the node with the beam elements [16]. To facilitate vehicle's passage over US 78, a set of beam elements was created on the bridge surface underneath M1. This set of beam elements serves as a path for the vehicle, which transfers the dynamic vehicular axle loads to the bridge. The RAILTRAIN contacts were defined between beam elements under the vehicle wheels with the node located at M1. The RAILTRAIN track provides a mode to assign different types of surface roughness profiles to the bridges that are used for obtaining roughness effects on bridge responses. To this end, using different road surface roughness profiles (as shown in Figure 2), and the 3D SFEM of bridge and vehicle (as shown in Figures 4 and 6), the vehicle-bridge interaction was initiated and verified using experimental results as described in Section 3.

\section{Dynamic Vehicle-Bridge Interaction of US 78 with Heavy Vehicle Using 3D SFEM}

Dynamic vehicle-bridge interaction was carried out using already verified 3D SFEMs of US 78 and heavy vehicles in order to obtain dynamic responses of vehicle-bridge interaction in terms of time strain histories [15]. To obtain girder strain responses, four strain gauges known as weighing sensors were installed under the girder at the mid-span. Similarly, to obtain vehicular parameters such as number of axles, axle spacing, and vehicle velocity, four strain gauges known as Free of Axle Detector (FAD) sensors were placed under the slab as shown in Figure 7.

As shown in Figure 7, W represents a weighing sensor at the mid-span. The FAD sensors were placed under the slab so that there are two FAD sensors falling in the same lane and line, $3.7 \mathrm{~m}$ away from each other. From Figure 7, it can be observed that, for the US 78, FAD sensors were placed in $\mathrm{L} 1$ and $\mathrm{L} 2$ ( $\mathrm{L}=$ lane; $\mathrm{G}=$ girder). As shown in Figure 7, the position of the heavy vehicle in L1 of US 78 was used for obtaining weighing and FAD sensor responses. The vehicle position in Figure 7 accurately reflects the vehicle position used for the experimental test. The times strain histories were obtained for US 78 with the vehicle velocity being $88 \mathrm{~km} / \mathrm{h}$ (55 mph). In case of the US 78, the vehicle is over G1 and G2 and therefore, using the 3D SFEM, the strains were obtained from the weighing sensors for these girders and compared with experimental strain as shown in Figures 8(a) and 8(b).

From Figures 8(a) and 8(b), it can be observed that the 3D SFEM showed strain patterns similar to the experimental strain for US 78. The G1 of US 78 showed 6\% less response, compared to experimental strain, and the G2 showed $18 \%$ higher strain responses than the experimental strain. Since the values of first peak responses were consistent in all the cases, only these values were considered for the comparison [15]. Overall, the responses of the first peak values obtained from 3D SFEM for US 78 were within acceptable limits.

In addition to these responses, the responses of FAD sensors were obtained for identification of vehicle parameters. The goal of the FAD sensor is to identify the peak responses in order to represent the individual axles. Therefore, the magnitudes of the peak responses were neglected and only the peak response pattern was used for vehicle and velocity identification. For the FAD sensor responses, it was observed from previous analysis, using 3D Finite Element Model (3D FEM) of US 78 and heavy vehicle that when the vehicle path is near or above the girder, the responses are poor [15]. For this scenario, the sensor optimization was carried out to determine the ideal sensor location near the girder for detecting vehicle parameters [17]. Using already optimized sensor locations on the slab from previous studies, further analysis was carried out on a scenario where the vehicle paths for US 78 were over or near the girder, as shown in Figure 7. The sensor locations selected for FAD response on US 78 bridge are as shown in Figure 9.

From Figure 9, it can be observed that, for US 78, the FAD sensors were located at $0.25 L$ from each end $(L$, length of test span) and at $0.25 \mathrm{WS}$ (WS, Width of test span or distance between the girders). The responses for the vehicle position (as shown in Figure 7) and sensor position (as shown in Figure 9) were obtained using FAD sensors, as shown in Figure 10.

As shown in Figure 10, the responses obtained for US 78 are the bridge responses before applying any filters on the strain responses. From Figure 10 it can be observed that the unfiltered sensor data showed a significant amount of vibration and the axles were unrecognized (designated as UR). Both sensors showed significant vibration thus making distinction of rear axles impossible. In order to remove the excessive vibration and noise due to vehicle movement on US 78, the Butterworth Filter, also known as the maximum flat magnitude filter, was selected for filtering the vibration responses of the FAD sensors. The Butterworth Filter is designed to provide flat frequency responses and the maximum flatness can be achieved for the filtered data with the use of Butterworth Filter [18-20]. The Butterworth Filter provides smooth responses for the frequencies and maximum flatness to the curve which was helpful in minimizing the vibration responses near axle locations [21-23]. Using Butterworth Filter, the excessive vibration was filtered out from the strain responses as shown in Figure 11. 


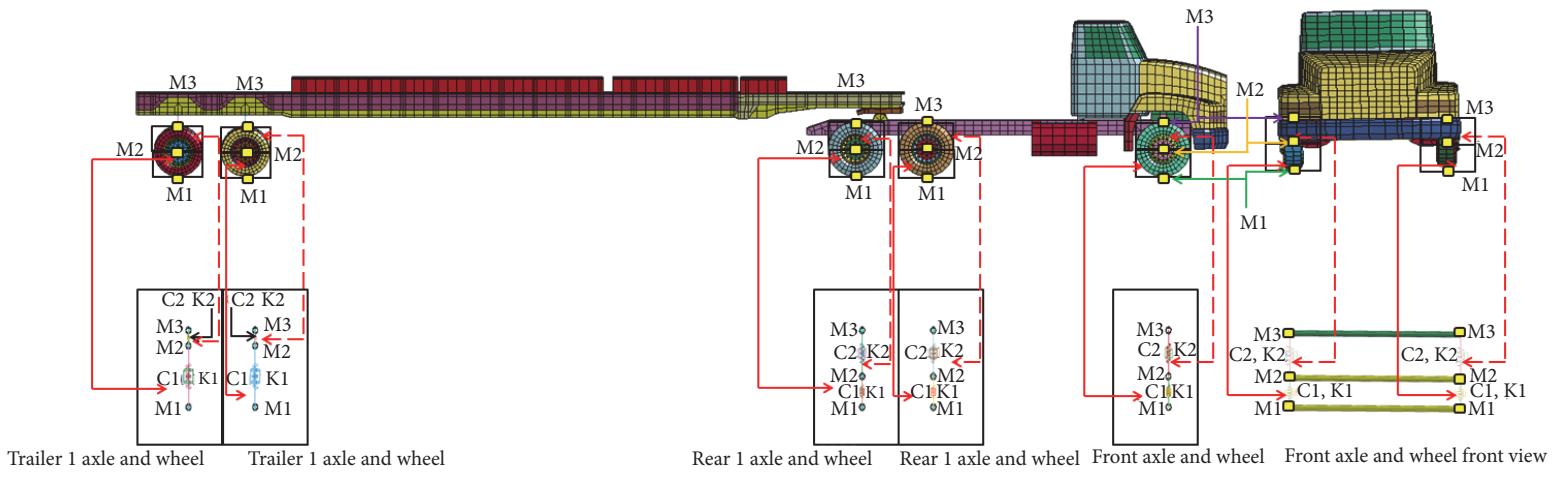

(a)

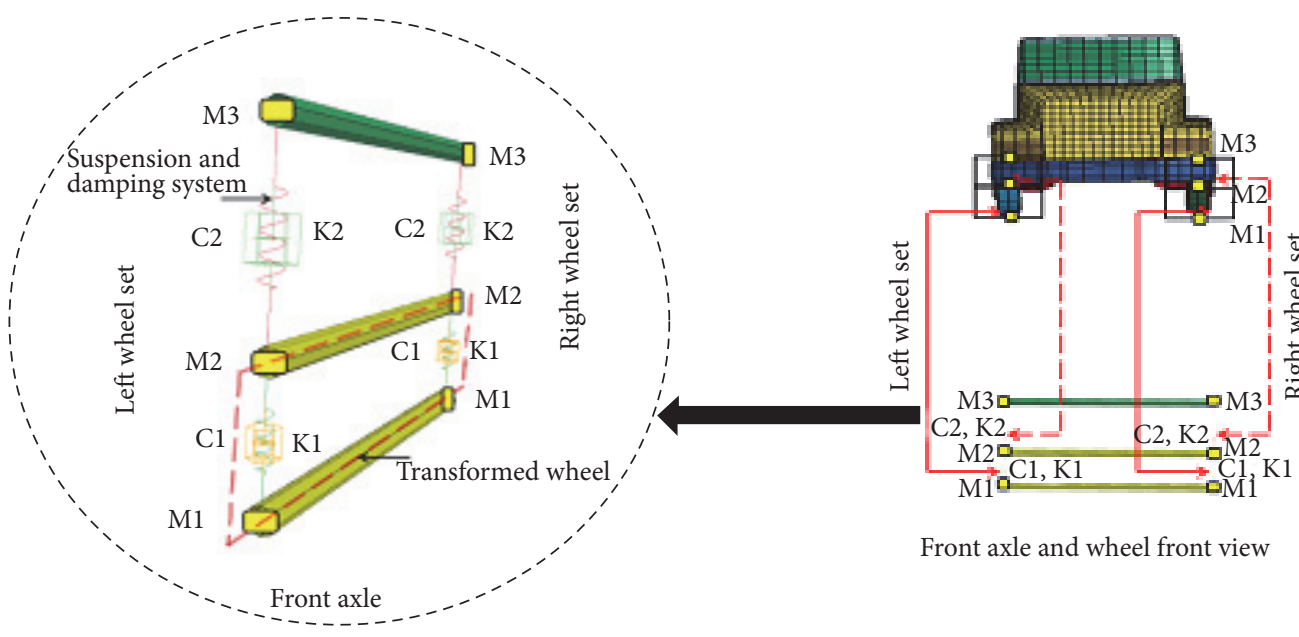

(b)

FIGURE 6: (a) 3D SFEM spatial model of ALDOT 5 axles truck created from 3D FEM. (b) Detailed schematic of the 3D SFEM of the front axle (spatial system).

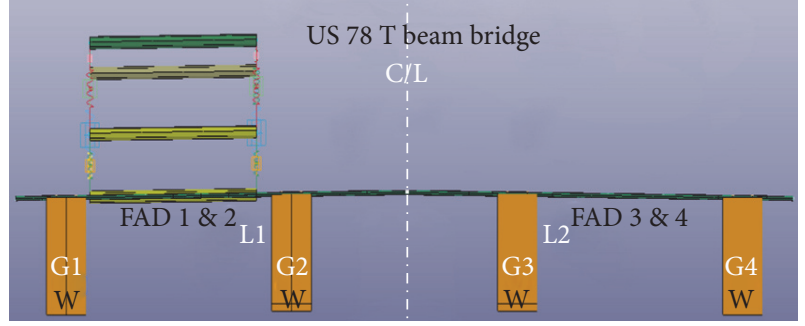

FIGURE 7: Positions of heavy vehicle on US 78 for vehicle-bridge interaction.

The filtered responses as shown in Figure 11 for US 78 showed clear peak values for the axles of heavy vehicles. All five axles were detected with the velocity within acceptable limits, Moreover, the axle distances were measured and verified with the measured distances as shown in Table 3 .

As observed from Table 3, the FAD sensor responses were in acceptable limit for MSR profile, with a maximum of $3 \%$ difference observed between measured responses and responses obtained from 3D SFEM for A3-A4. All the responses are in the acceptable limit, however, the bridge road surface is always subjected to continuous tire friction which increases the road surface roughness. Therefore, it is very important to address the issues of effect of variable road surface roughness on bridge performance. To this end, the investigation of effect of roughness on the bridge was carried out using road surface roughness profiles as shown in Figure 2. The responses of weighing sensors and FAD sensors were obtained under variable road surface roughness profiles in order to identify the axles over the bridge while the vehicle is in motion as described in Section 4.

\section{Effect of Surface Roughness on the Responses of the Bridge}

In order to obtain the effect of the road surface roughness on the bridge's response, the 3D SFEM was assigned the roughness profiles as shown in Figure 1. The weighing sensor responses for G1 were obtained for the scenario of a single vehicle over US 78. The weighing sensor responses on G1 of the US 78 bridge are as shown in Figures 12(a)-12(f).

From Figures 12(a)-12(f), it can be observed that, with the increase in the surface roughness from very good to 
TABLE 3: Comparison of FAD sensor response.

\begin{tabular}{lcccccc}
\hline Type & $D(\mathrm{~m})$ & $V(\mathrm{~m} / \mathrm{s})$ & A1-A2 & A2-A3 & A3-A4 & A4-A5 \\
\hline Measured & 6.25 & - & 4.27 & 1.32 & 11.54 & 1.22 \\
3D SFEM (MSR) & 6.125 & 24.5 & 4.43 & 1.35 & 11.15 & 1.23 \\
\hline
\end{tabular}

A1-A2, A2-A3, A3-A4, and A4-A5 are the distances between Axle 1-Axle 2, Axle 2-Axle 3, Axle 3-Axle 4, and Axle 4-Axle 5 in meters.

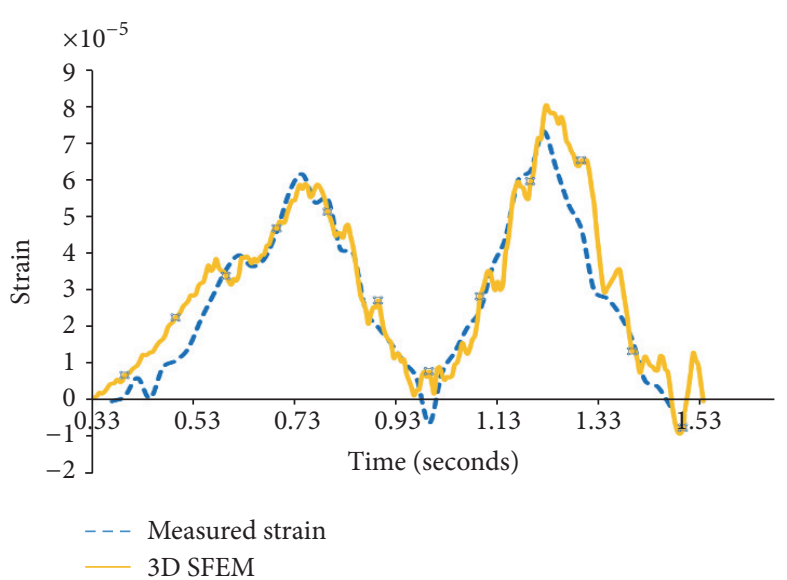

(a) Time strain histories for G1 of US 78

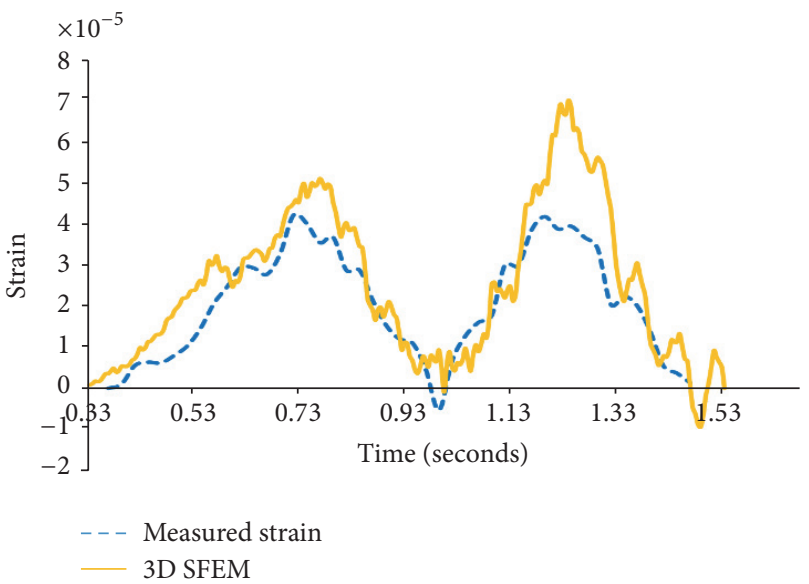

(b) Time strain histories for G2 of US 78

FIgURE 8: Time strain histories for US 78.

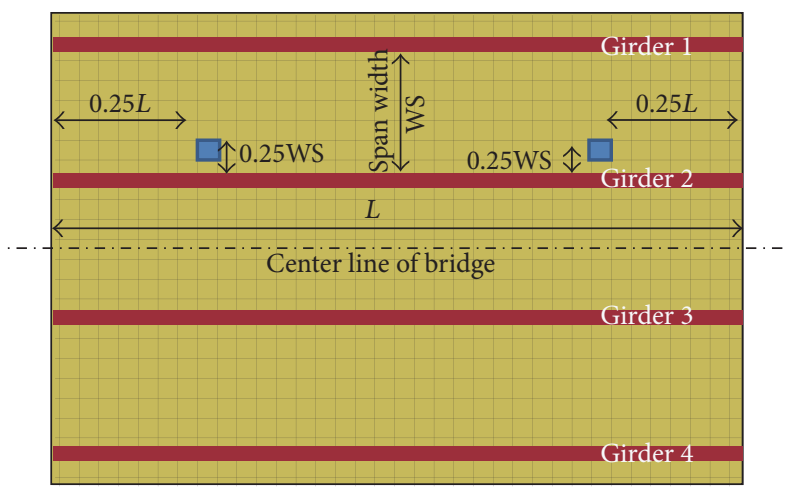

FIGURE 9: FAD sensor locations on US 78.

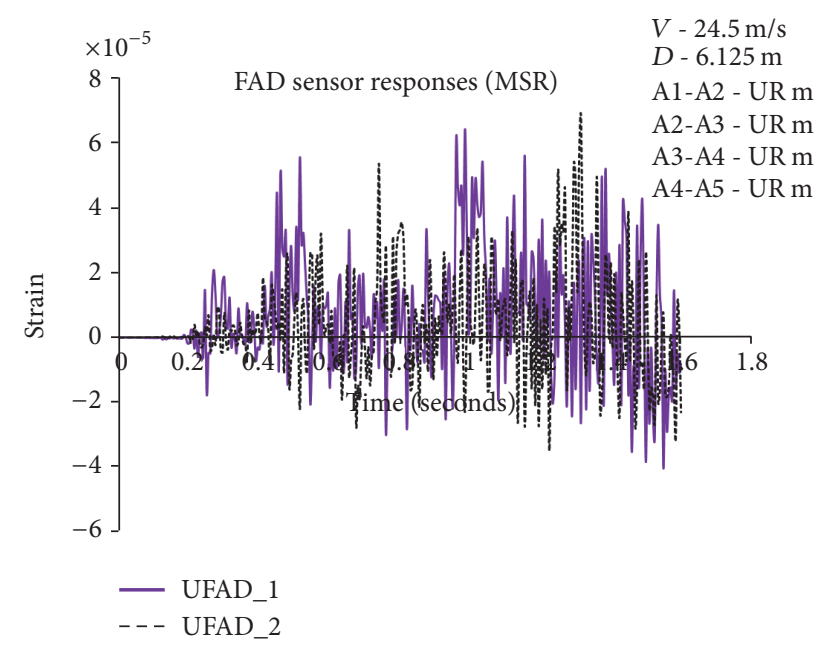

FIGURE 10: FAD sensor responses for US 78.

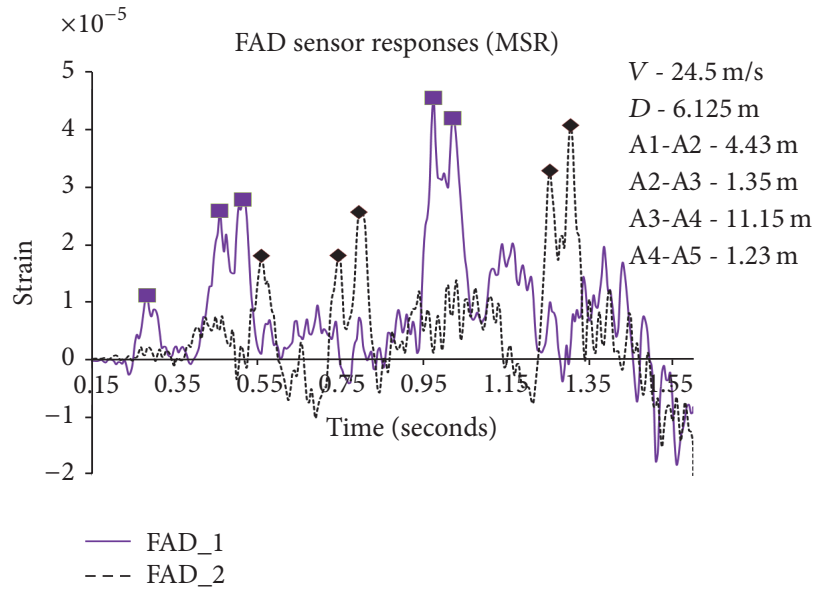

FIGURE 11: Filtered FAD sensor responses for US 78.

very poor, the vibration in the strain responses increased significantly. The strain obtained from the examples of good surface roughness (GSR), very good surface roughness (VGSR), measured surface roughness (MSR), and average surface roughness (ASR) showed less vibration in the curve.

The strain obtained from the examples of good surface roughness (GSR); very good surface roughness (VGSR); and measured surface roughness (MSR); and average surface roughness (ASR) showed less vibration in US 78 compared to poor surface roughness (PSR) and very poor surface roughness (VPSR). The DAF was obtained based on weighing sensor responses as shown in Figure 12. For the DAF, the static strain responses were obtained by positioning the vehicle in such a way that the maximum load accumulates at the 


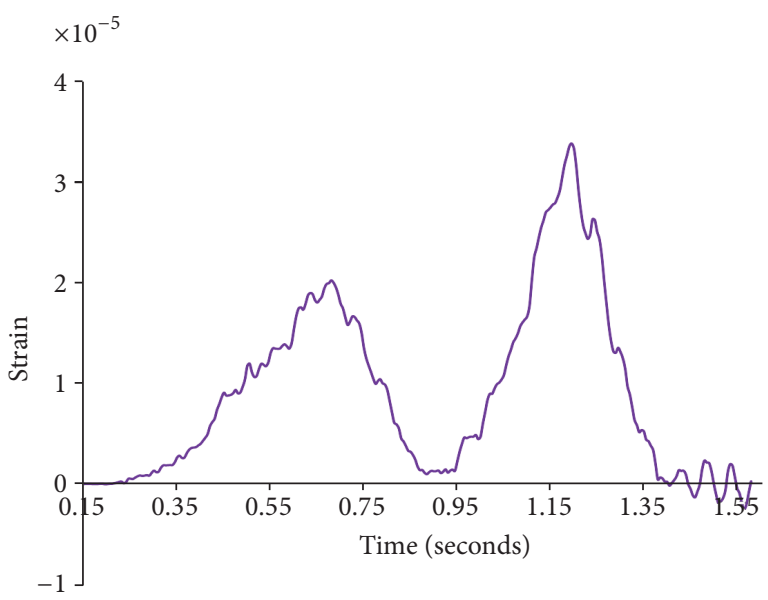

- Girder 1

(a) Weighing sensor response with MSR profile

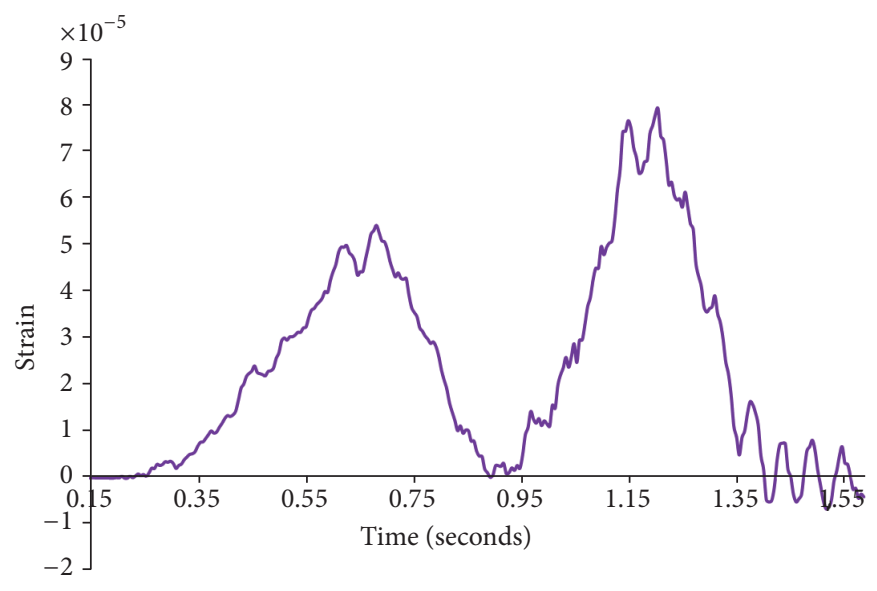

- Girder 1

(c) Weighing sensor response with GSR profile

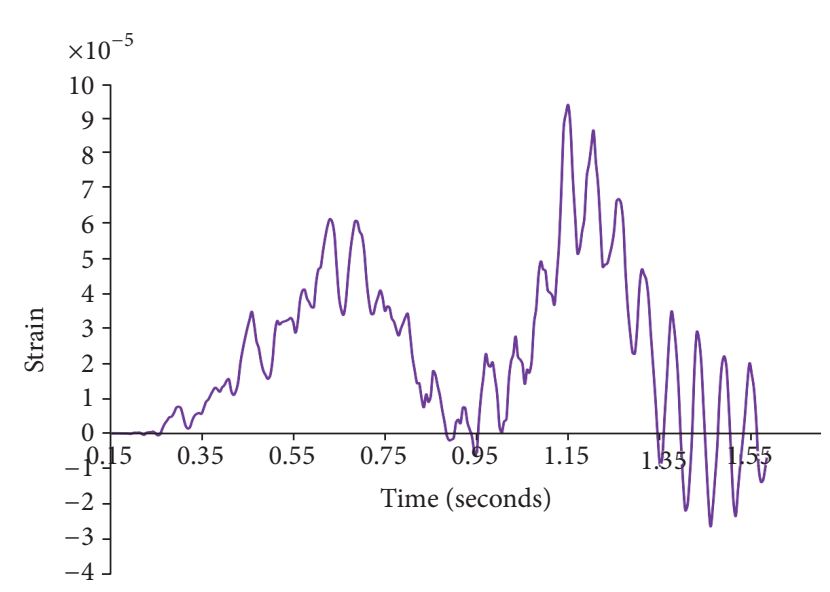

- Girder 1

(e) Weighing sensor response with PSR profile

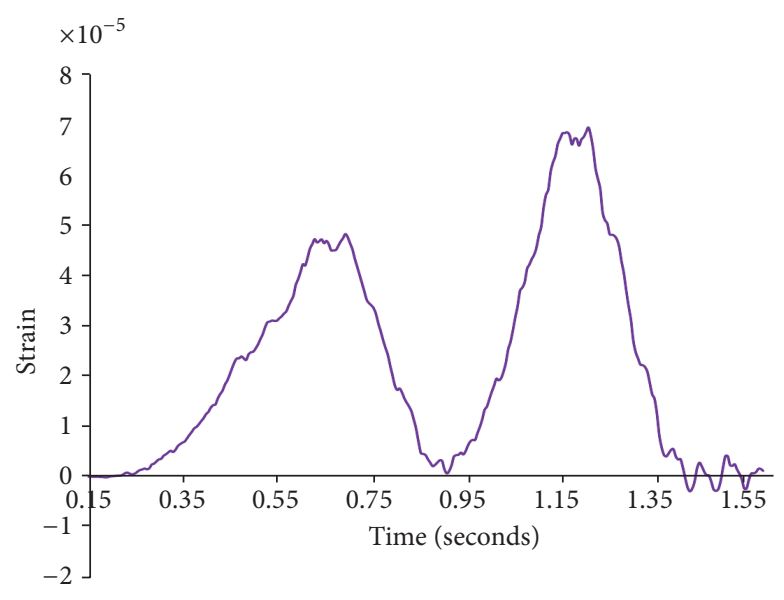

- Girder 1

(b) Weighing sensor response with VGSR profile

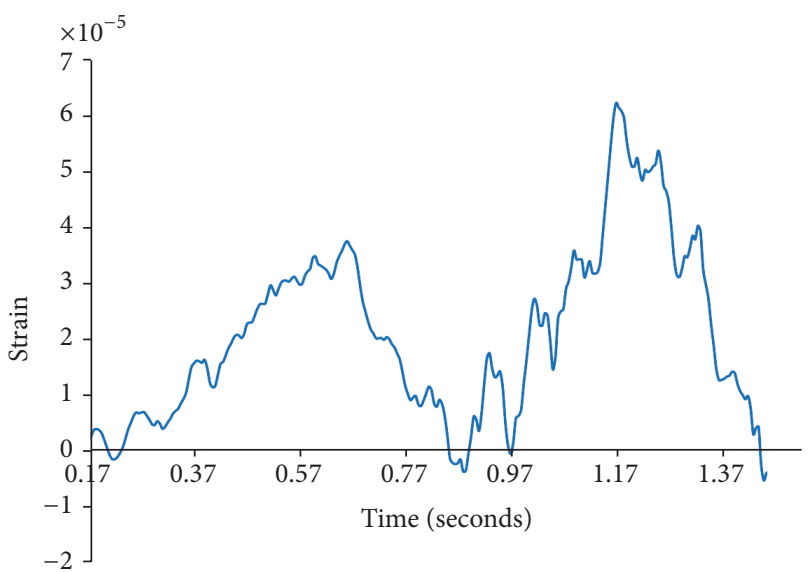

— Girder 1

(d) Weighing sensor response with ASR profile

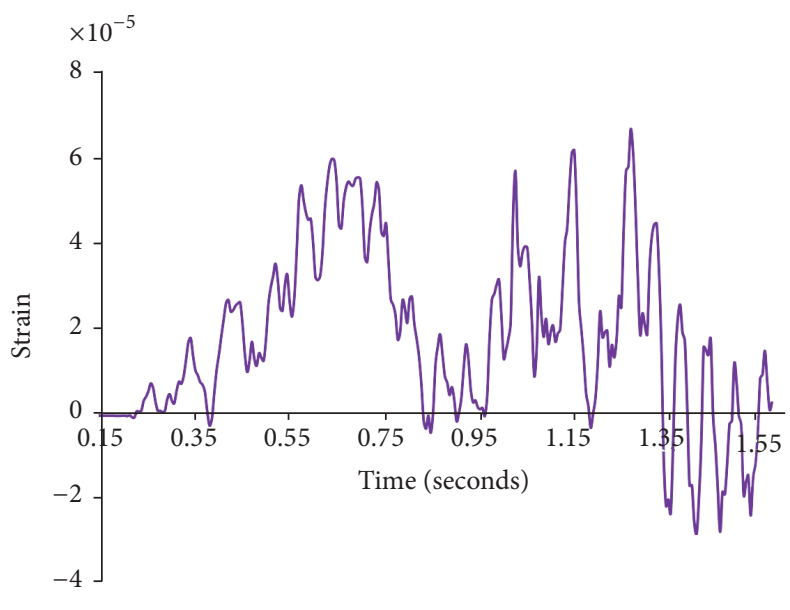

- Girder 1

(f) Weighing sensor response with VPSR profile

FIGURE 12: Weighing sensor responses for different surface roughness profiles on US 78. 


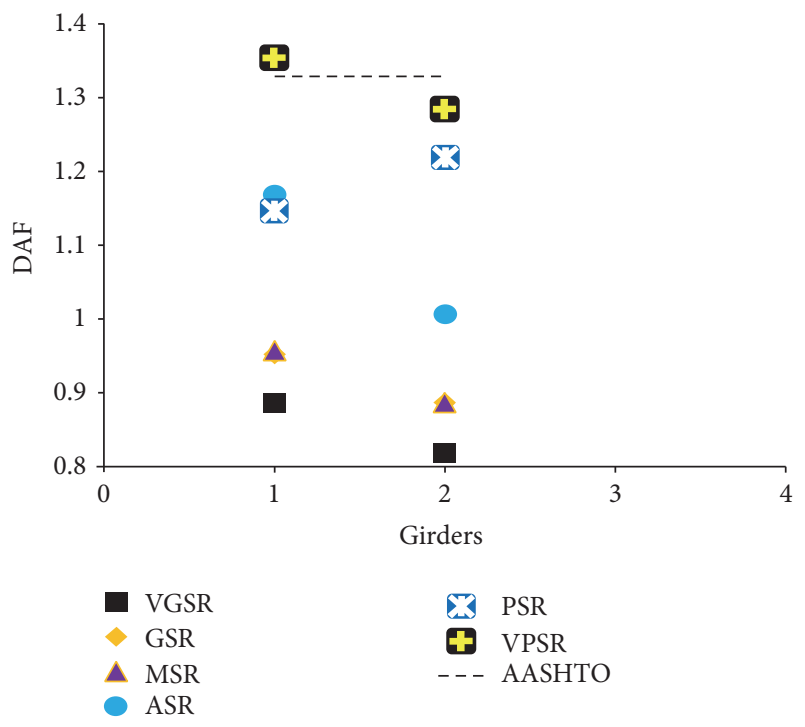

FIGURE 13: Effect of surface roughness on DAF of US 78.

center [21]. Using this approach to static strain, the DAF was obtained for each case of surface roughness as shown in Figure 13.

As seen from Figure 13 for US 78, the value of the DAF was increased significantly with the increase in surface roughness. The increase in the surface roughness was found to be proportional to the vibration of the bridge, where the $\mathrm{DAF}$ is the ratio of dynamic and static strain. From Figure 13 the VPSR produced the largest increase in DAF ( $45 \%$ for G1 of US 78). To amend this study, in order to investigate the effect of surface roughness on axle detection, further analysis was carried out on US 78 bridge and strain responses were obtained for the FAD sensors. Figures 14(a)-14(f) show the FAD sensor responses for FAD_1 and FAD_2 using variable roughness profiles.

As shown in Figures 14(a)-14(f), for the VGSR, GSR, MSR, and ASR profiles, at least one FAD sensor showed clear peak responses and satisfactory axial distances. However, in the case of PSR and VPSR, the axial distances were unrecognized due to excessive vibrations even after applying the filter. From Figures 14(a)-14(f), it can be observed that for the US 78 the difference between Rear Axle 1 and Rear Axle 2 is $32 \%$ when comparing ASR to MSR. In the case of PSR and VPSR, the axle is undetectable. Although the axle detection for a single vehicle with VGSR, GSR, MSR, or ASR is valid, a bridge is always subjected to multiple vehicles which has made axle detection a great challenge. Therefore, to account for and resolve this difficulty, further analysis was carried out on multiple vehicles on US 78 using four surface roughness profiles (MSR, VGSR, GSR, and ASR). The arrangement of multiple vehicles over the bridges is as shown in Figure 15.

From Figure 15, it can be observed that the heavy vehicle path in US 78 is above the girders. In the case of the US 78, the strain responses were obtained for G1 to G4. For the sake of brevity, only the weighing sensor responses located on G2 and G3 of US 78 were obtained and interpreted for further analysis. The strain responses for US 78 are as shown in Figures 16(a)-16(d).

From Figures 16(a)-16(d), it can be observed that, for US 78 with multiple vehicles over it, bridge responses showed significant vibration compared to the single vehicle scenario. Based on the weighing sensor responses for US 78 with multiple vehicles, the DAF was obtained for the variable road surface roughness profiles as shown in Figure 17.

From Figure 17, it can be observed that with the surface roughness changed from very good to average, the DAF values for each girder increased. In all the cases, the DAF values were found to be less than specified by the AASHTO design code, except in the case of ASR, where DAF values obtained were on the higher side. Based on this information, the following conclusions can be made as described in Section 5.

\section{Conclusion}

Based on the studies carried out on US 78 using the spatial system, the following conclusions were drawn:

(i) The spatial system of finite element modeling was successfully implemented in the analysis of the reinforced concrete US $78 \mathrm{~T}$ beam bridge, using vehiclebridge interaction with variable road surface roughness profiles.

(ii) The strain responses observed from the 3D SFEM showed close resemblance with the experimental strain responses from the weighing sensors.

(iii) In the case of single heavy vehicle over the bridge the peak strain responses were obtained within satisfactory limits from the FAD sensors.

(iv) The application of variable surface roughness was carried out and the strain responses were obtained for a single vehicle over the US 78 using weighing sensors and FAD sensors. Values for DAF were obtained for the scenario of a single heavy vehicle over US 78 where $45 \%$ increase in the DAF for the G1 was observed when surface roughness changed to VPSR from MSR.

(v) The vehicle axle detection for the single vehicle over the bridge was observed to be within acceptable limits for the road surface profiles VGSR, GSR, MSR, and ASR. The PSR and VPSR failed to allow for recognition of the distance between axles.

(vi) Since the road surface roughness profiles VGSR, GSR, MSR, and ASR successfully detected the axles and distances between them, these surface roughness profiles were analyzed for a multiple vehicle scenario, and weighing and FAD sensor responses were observed.

(vii) From weighing sensor responses with multiple vehicles over the bridge the values of the DAF were obtained for US 78 bridge. In case of US 78 , an extreme DAF value was obtained for G3 using ASR, where the DAF was 3.75\% lower than specified by AASHTO. Based on the simulations and observations 


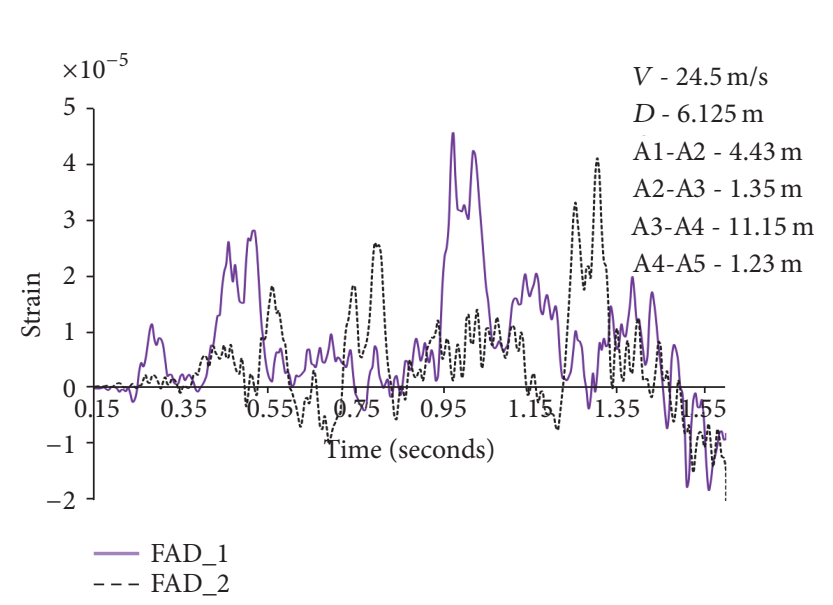

(a) FAD sensor response with MSR profile

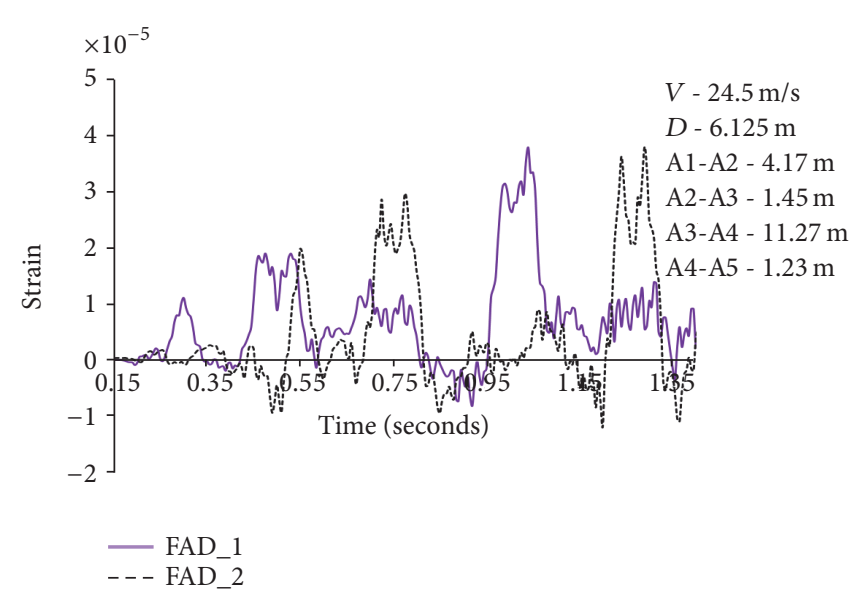

(c) FAD sensor response with GSR profile

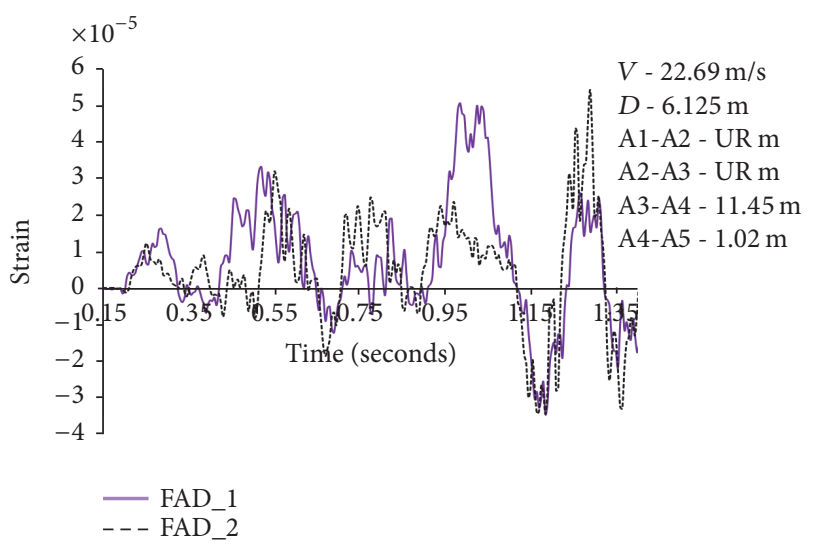

(e) FAD sensor response with PSR profile

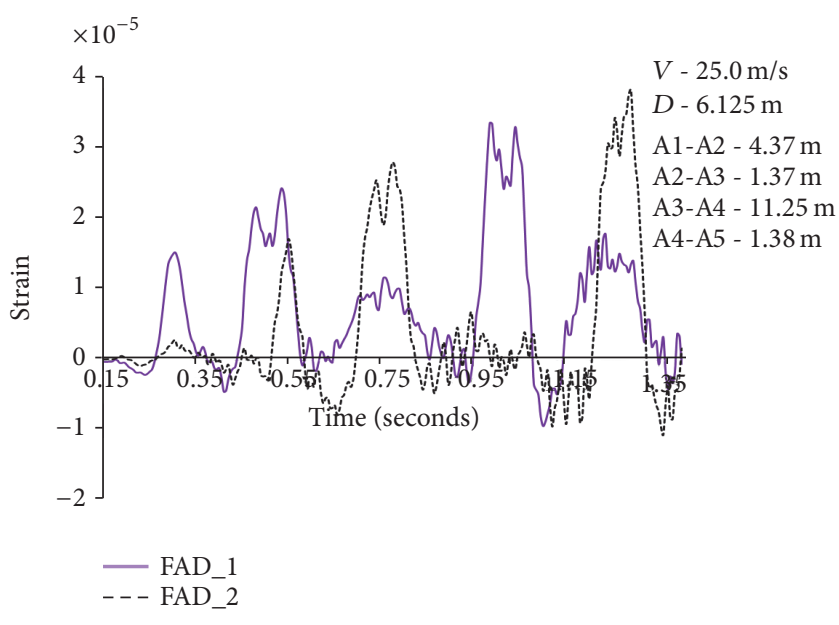

(b) FAD sensor response with VGSR profile

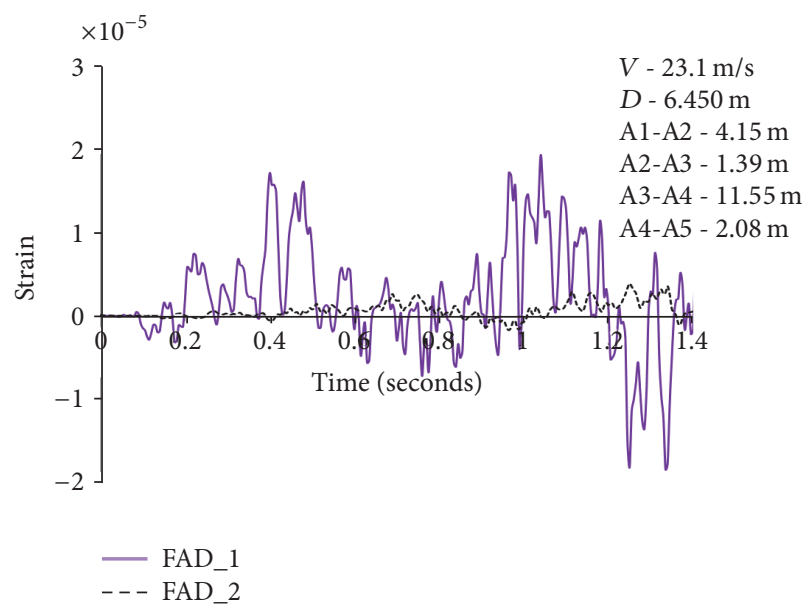

(d) FAD sensor response with ASR profile

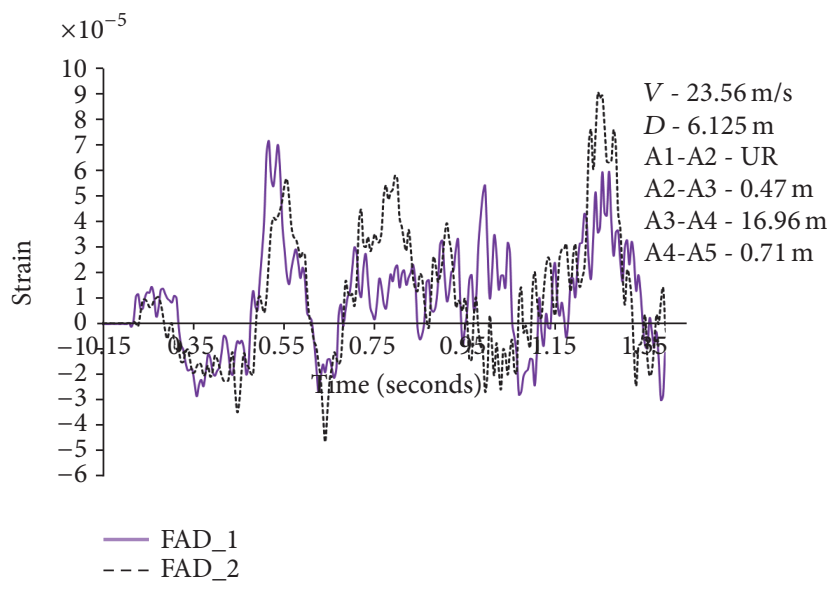

(f) FAD sensor response with VPSR profile

FIGURE 14: FAD sensor responses of US 78 with poor road surface roughness.

conducted, it can be concluded that the surface roughness effects on US $78 \mathrm{~T}$ Beam Bridge produced reliable responses for the DAF and for axle detection for the VGSR, GSR, and MSR profiles, and for the ASR profile the reliable responses were observed only when subjected to one vehicle. In case of multiple vehicle scenarios, the ASR showed significant vibration in the strain responses, and the values for the DAF were observed to increase radically, and the axle detection was observed to be unreliable. 


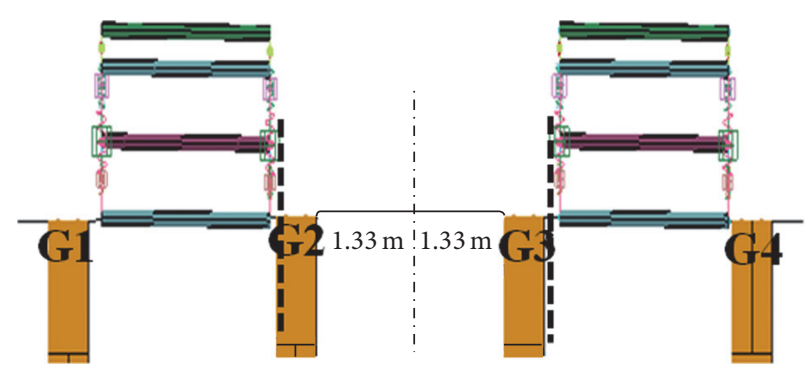

FIGURE 15: Multiple vehicles over US 78 bridge.

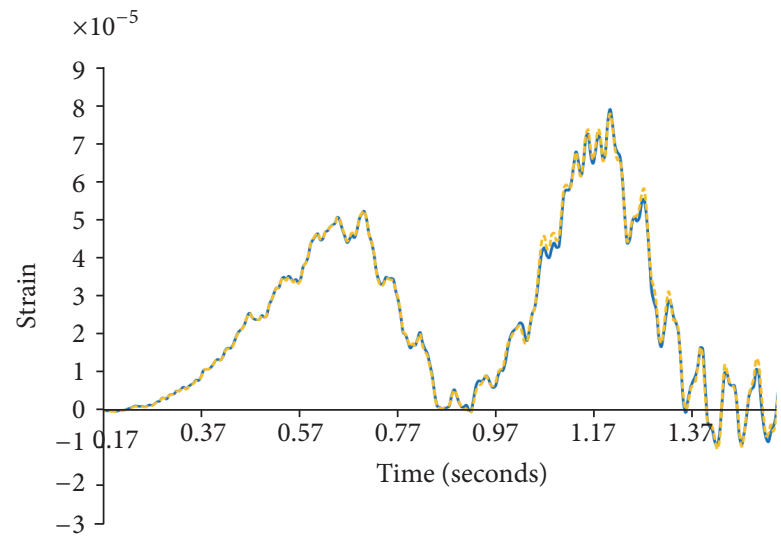

- Girder 2

Girder 3

(a) Weighing sensor response for VGSR

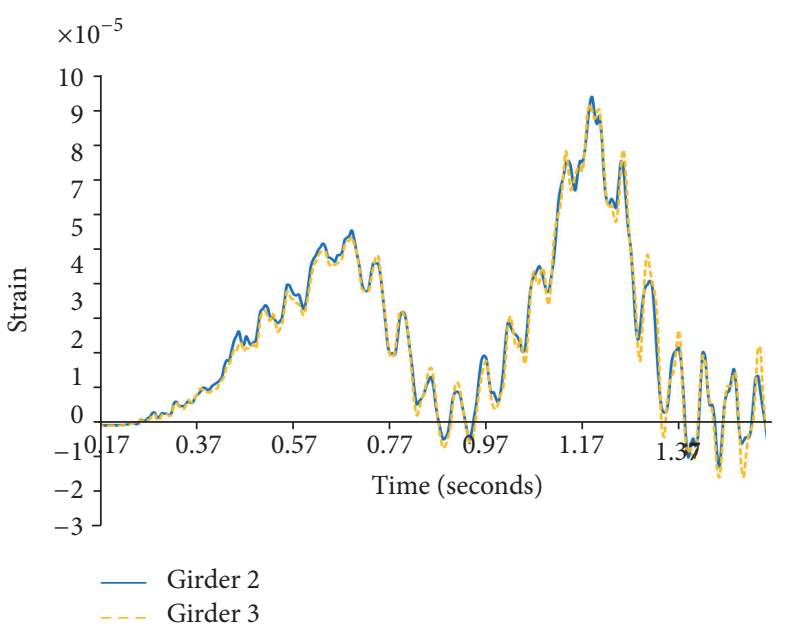

(c) Weighing sensor response for MSR

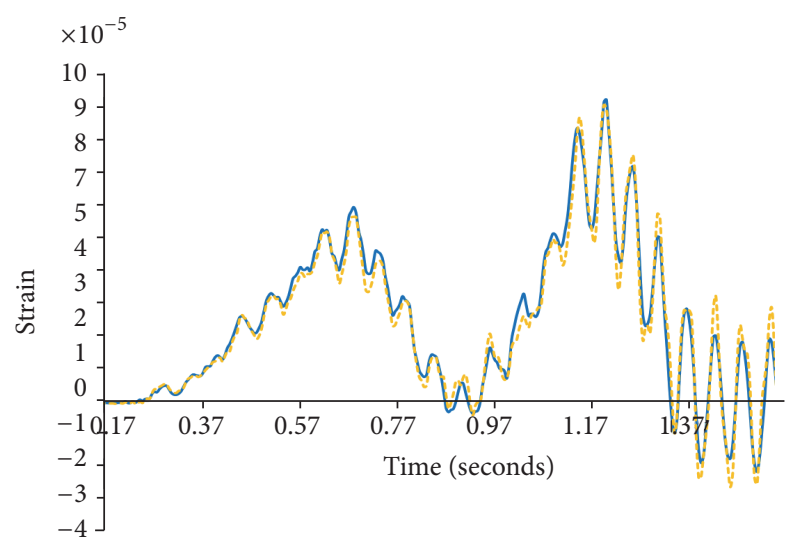

Girder 2

Girder 3

(b) Weighing sensor response for GSR

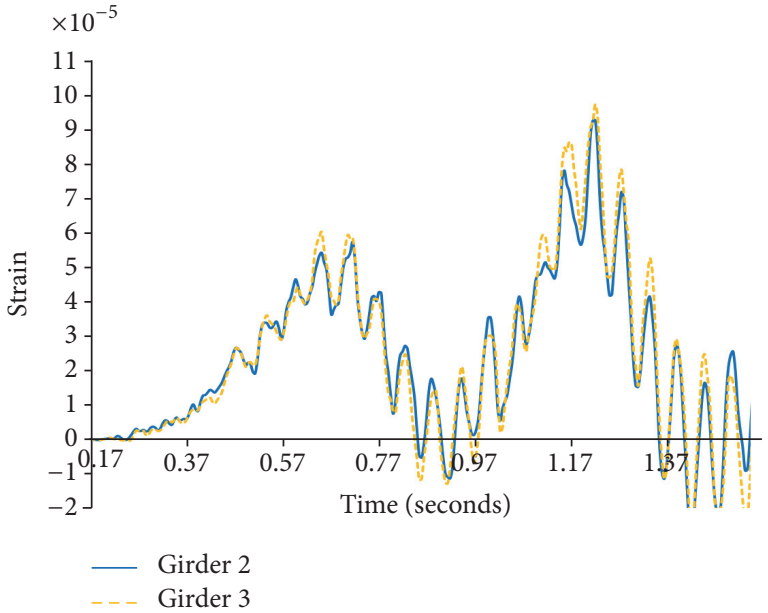

(d) Weighing sensor response for ASR

FIGURE 16: Weighing sensor responses on US 78 with multiple vehicle scenario. 


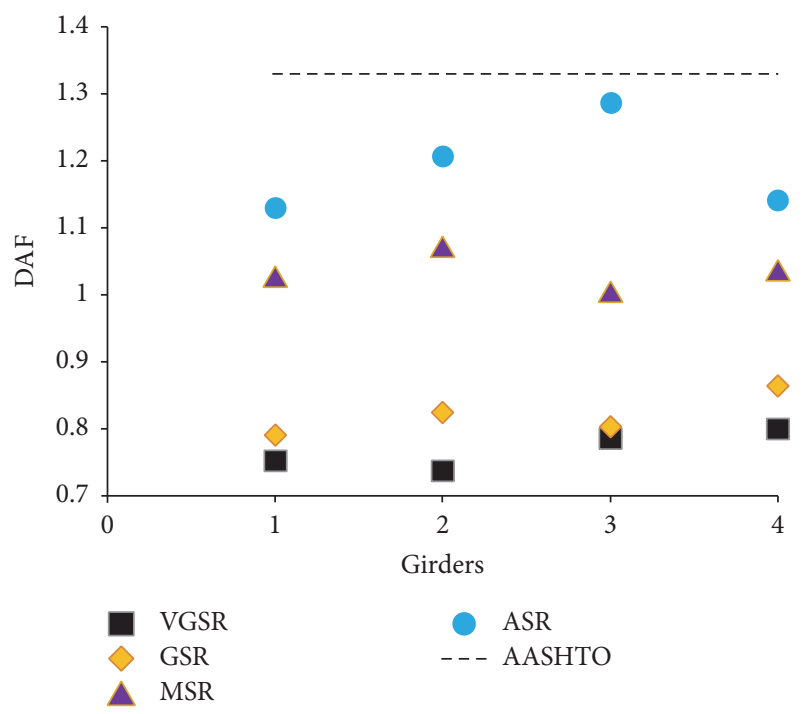

FIGURE 17: Effect of surface roughness on the DAF of US 78 with multiple vehicles.

Using the data presented in this research article, the responses of the bridges can be used for obtaining the effects of surface roughness on any type of bridges in terms of DAF and axle detectability. With these studies, the implementation of different surface roughness profiles can be possible for accurately predicting bridge responses. Moreover, with the development of 3D SFEM vehicle-bridge interaction and the implementation of surface roughness in the 3D SFEM, the resulting responses can be used in selection of the bridge for experimental B-WIM implementation.

\section{Competing Interests}

The authors declare that they have no competing interests.

\section{Acknowledgments}

The authors would like to express their gratitude for the financial support received from National Science Foundation (NSF-CMMI-1100742) towards this investigation.

\section{References}

[1] M. Yener and K. Chompooming, "Numerical studies of vehiclebridge systems," Structural Engineering and Mechanics Division Report CEE-SEMD-91-13, Utah State University, 1991.

[2] J. Fleming and P. Romualdi, "Dynamic response of highway bridges," Journal of Structural Engineering (ASCE), vol. 87, pp. 31-61, 1961.

[3] E. C. Ting and M. Yener, "Vehicle-structure interactions in bridge dynamics," Shock and Vibration Digest, vol. 15, no. 12, pp. 3-9, 1983.

[4] M. Yener and K. Chompooming, "An overview on vehiclebridge interaction problems and optimum design of bridge systems," Tech. Rep. CEE-SEMD-91-09, Utah State University, 1991.
[5] J. G. S. da Silva, "Dynamical performance of highway bridge decks with irregular pavement surface," Computers \& Structures, vol. 82, no. 11-12, pp. 871-881, 2004.

[6] X. Q. Zhu and S. S. Law, "Dynamic load on continuous multilane bridge deck from moving vehicles," Journal of Sound and Vibration, vol. 251, no. 4, pp. 697-716, 2002.

[7] American Association of State Highway and Transportation Officials, AASHTO LRFD Bridge Design Specifications, American Association of State Highway and Transportation Officials, Washington, DC, USA, 4th edition, 2010.

[8] R. K. Gupta, "Dynamic loading of highway bridges," American Society of Civil Engineers, Journal of Engineering Mechanics, vol. 106, pp. 377-393, 1980.

[9] S. Jerath and S. B. Gurav, "Impact factors for highway bridges using road surface roughness and vehicle dynamics," Modern Traffic and Transportation Engineering Research, vol. 2, no. 2, pp. 113-120, 2013.

[10] International Standard Organization, "Mechanical vibration: road surface profiles-reporting of measured data," Tech. Rep. ISO 8068 (E), International Standard Organization, Geneva, Switzerland, 1995.

[11] S. Abdalmaged, Dynammic analysis and fatigue assessment of bridge decks subjected to traffic and corronsion effects [M.S. thesis], Department of Civil and Environmental Engineering, Colorado State University Fort Collins, Fort Collins, Colo, USA, 2013.

[12] Cebon, Handbook of Vehicle-Road Interaction, Swets and Zeitlinger, 1999.

[13] W. Han, J. Wu, C. S. Cai, and S. Chen, "Characteristics and dynamic impact of overloaded extra heavy trucks on typical highway bridges," Journal of Bridge Engineering, vol. 20, no. 2, 2015.

[14] I. Vayas, A. Iliopoulos, and T. Adamakos, "Spatial systems for modelling steel-concrete composite bridges-comparison of grillage systems and FE models," Steel Construction, vol. 3, no. 2, 2010.

[15] R. Kalyankar, Simulation of bridge responses to heavy vehicles [Ph.D. thesis], Department of Civil Construction and Environmental Engineering, the University of Alabama at Birmingham, Birmingham, Ala, USA, 2015.

[16] LS-DYNA Keyword User's Manual Volume 1, Version 971, Livermore Software Technology Corporation, Livermore, Calif, USA, 2007.

[17] R. Kalyankar and N. Uddin, "Optimization of free of axle detector sensor location using 3D finite element simulations for bridge weigh in motion system on US girder bridges," Journal of Structural Control and Health Monitoring, In press.

[18] S. Butterworth, "On the theory of filter amplifiers," Experimental Wireless and the Wireless Engineer, vol. 7, pp. 536-541, 1930.

[19] K. Lacenette, A Basic Introduction to Filters-Active, Passive, and Switched Capacitors, National Semiconductor Application Note 779, 1991.

[20] G. Bianchi and R. Sorrentino, Electronic Filter Simulation and Design, McGraw-Hill, 2007.

[21] Web article, https://zone.ni.com/reference/en-XX/help/371361J-01/ lvanlsconcepts/lvac_butterworth_filters/.

[22] http://www.etc.tuiasi.ro/cin/Downloads/Filters/Filters.htm.

[23] http://www.radio-electronics.com/info/rf-technology-design/ rf-filters/butterworth-rf-filter-basics.php. 


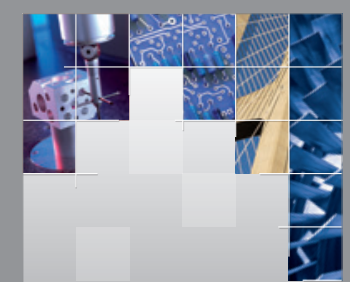

\section{Enfincering}
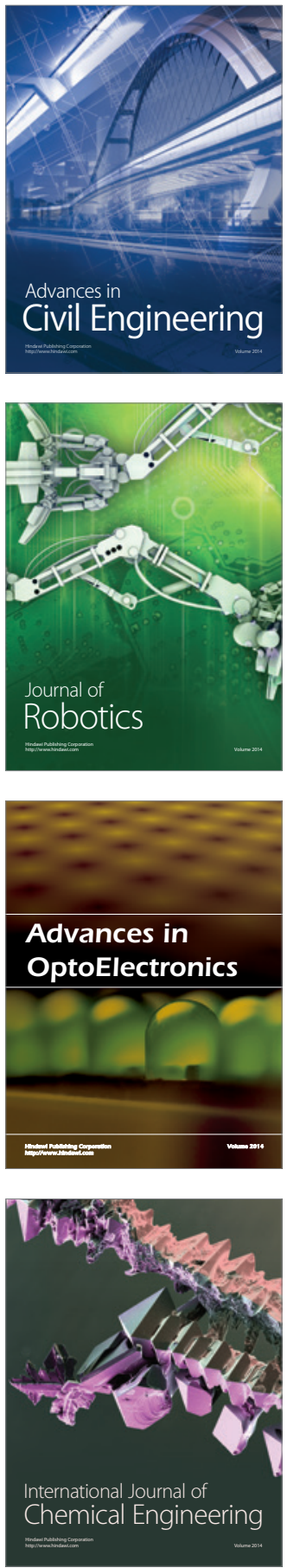

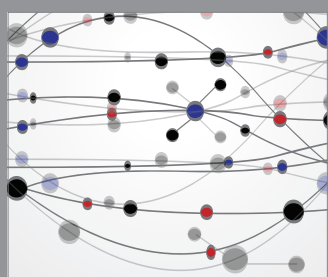

The Scientific World Journal

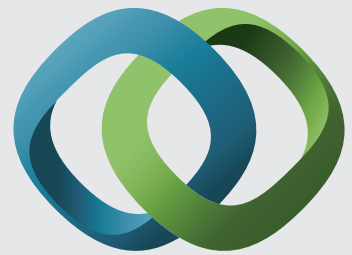

\section{Hindawi}

Submit your manuscripts at

http://www.hindawi.com
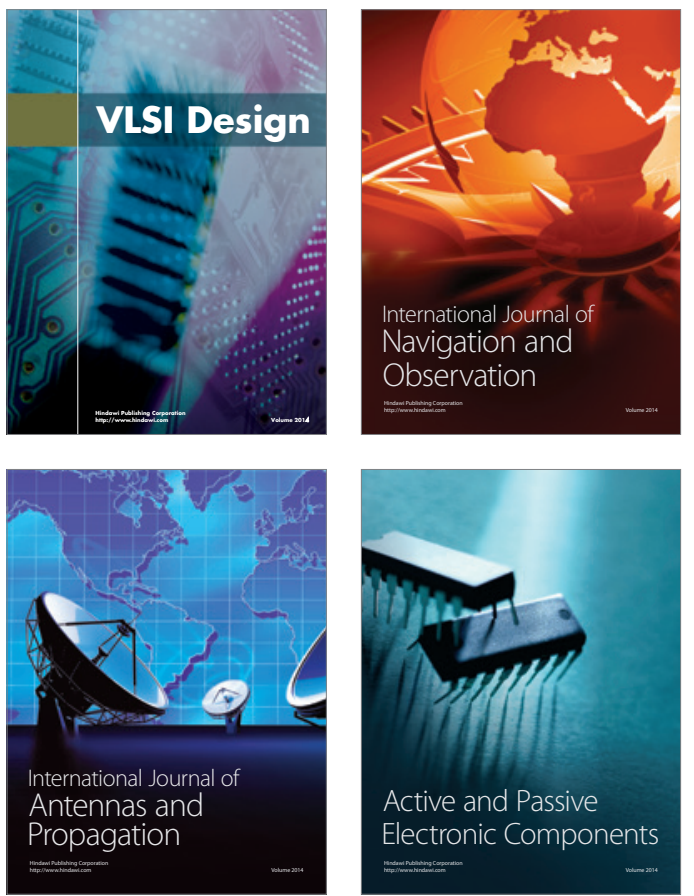
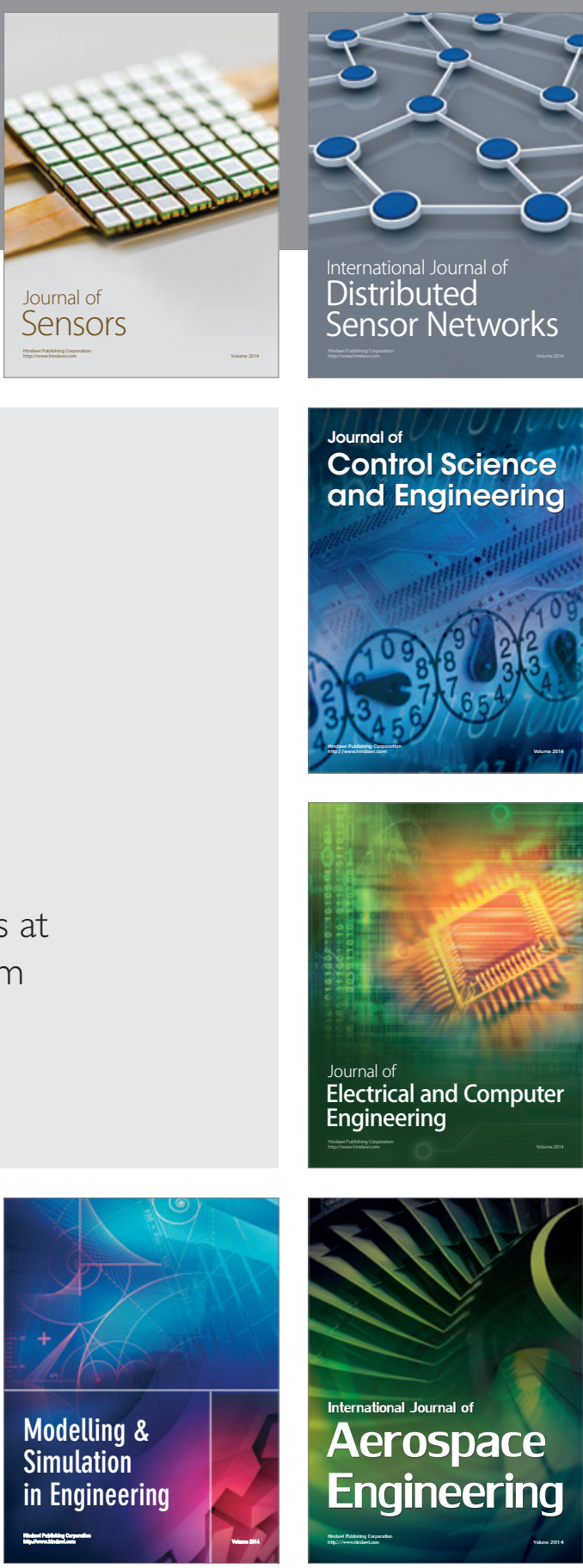

International Journal of

Distributed

Sensor Networks

Journal of

Control Science

and Engineering
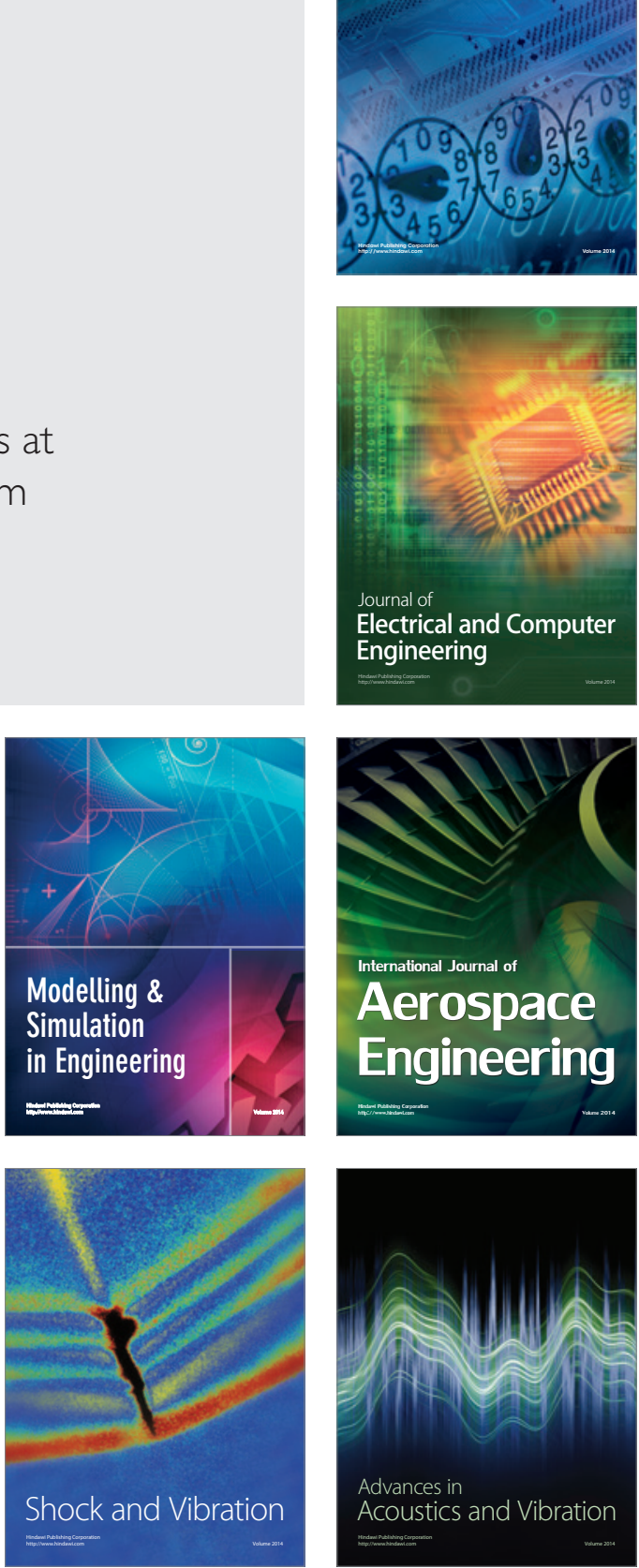